\title{
THE IMPACT OF WORKAHOLISM AND WORK ENGAGEMENT ON DISTANT LEARNING AND WORK-FAMILY GONFLIGT DURING THE GOUID-19 LOCKDOWN
}

\author{
Yura Loscalzo* \\ University of Florence, Florence, Italy
}

Please cite this article as:

Loscalzo, Y., 2021. The Impact of Workaholism and Work Engagement on Distant Learning and Work-Family Conflict During the COVID-19 Lockdown. Amfiteatru Economic, 23(58), pp. 752-769.

\section{Article History}

Received: 21 March 2021

Revised: 7 May 2021

Accepted: 29 June 2021

DOI: $10.24818 / \mathrm{EA} / 2021 / 58 / 752$

\begin{abstract}
This study aims to analyze how workaholism and work engagement influenced Distance Learning (DL) - as a subset of teleworking, work-to-family conflict (WFC), and negative affect in Italian teachers. Moreover, among other aims, it analyzes if teachers' perceived negative impact of DL on life influenced WFC and negative affect. Finally, it examines differences in DL-related variables concerning gender, area of living, type of school, and teacher type. A path analysis model and MANOVAs on 587 teachers $($ Mage $=48.80 \pm 9.17$ ) have been performed. Among the main findings, workaholism is a positive predictor of WFC, negative affect, and DL negative impact on work and life. Work engagement, instead, is a negative predictor of these variables and a positive predictor of DL perceived efficacy. However, workaholism is a stronger predictor than work engagement. Moreover, DL negative impact on life is a positive predictor of negative affect, while DL perceived efficacy for students negatively predicts it. Finally, DL negative impact on life predicts WFC. In conclusion, this study suggests that it is imperative to reduce workaholism (and increase study engagement) to improve teachers' well-being and work quality during DL. Moreover, Schools' Heads should implement training to help teachers to face the technical and educational issues posed by DL (especially for teachers working in kindergarten and secondary school and with children with special needs) to make them able to provide DL of good quality. They should also provide teachers with psychological support to help them cope with the distress felt due to the changes in their work, which affected their balance between work and life (especially in primary and secondary schools).
\end{abstract}

Keywords: Distance learning, heavy work investment, workaholism, work engagement, work-family conflict, school, teachers.

JEL Classification: I19

\footnotetext{
*Author’s contact - e-mail: yura.loscalzo@gmail.com
}

Author's ORCID:

Yura Loscalzo: orcid.org/0000-0002-5878-6769 


\section{Introduction}

This paper presents a study about the impact that workaholism and work engagement had on Italian teachers during the Distance Learning (DL; namely, a subset of teleworking) imposed by the COVID-19 pandemic and how DL affected their negative affect and worklife balance. It also analyzed some demographic (i.e., gender and area of living) and school (i.e., type of school and teaching) related differences in the following DL-related variables: DL efficacy for students, DL negative impact on work, and DL negative impact on life. Finally, it presents the Distance Learning Questionnaire (DLQ), a scale created as a preliminary step for conducting the main research.

\section{Review of the scientific literature}

\subsection{Heavy Work Investment}

Workaholism and work engagement are two types of Heavy Work Investment (HWI; Snir and Harpaz, 2012) addressed in recent years by many authors, focusing on its antecedents and outcomes and both workers and students (e.g., van Beek et al., 2013; van Beek, 2014; Houlfort et al., 2014; Schaufeli, 2016; Rabenu and Aharoni-Goldenberg, 2017; Babic et al., 2019; Loscalzo and Giannini, 2019; Rabenu et al., 2019; Tziner et al., 2019; Ivancevic et al., 2020; Loscalzo, 2021;).

Among the scholars who analyzed HWI, Loscalzo and Giannini (2017a) suggested that workaholism and work engagement might be co-present in some workers, in line with van Beek et al. (2011). Hence, they propose distinguishing between engaged workaholics (who have high workaholism and work engagement) and disengaged workaholics (that is, workers with high workaholism and low work engagement). Furthermore, Loscalzo and Giannini (2017a) - adopting a clinical psychological perspective in reviewing workaholism literature - defined workaholism as a clinical condition characterized by both externalizing (or addiction) and internalizing (or obsessive-compulsive) symptoms. Interestingly, through a recent study concerning the role of internalizing and externalizing symptoms as both antecedents and outcomes of HWI, they found that Psychoticism positively predicts workaholism, hence speculating that workaholism might also be defined as the declination at work of a personality disorder, such as Schizoid or Obsessive-Compulsive Personality Disorder (Loscalzo and Giannini, 2020a).

In brief, some scholars recently argued that "most of the currently existing conceptualizations of work addiction (explicitly or implicitly) define it as a behavioral addiction" (Atroszko et al., 2019; p.9). However, it seems vital Loscalzo and Giannini's (2017a) suggestion about studying problematic overworking without an a priori addictionrelated theoretical framework to highlight its real characteristics (in line with KardafelthWinther, 2015). In fact, Loscalzo and Giannini (2020a) underlined that, besides considering both the internalizing and/or externalizing nature of workaholism, scholars should also consider the possibility of conceptualizing workaholism as a work-related declination of a personality disorder. Hence, other studies on workaholism's real nature should be carried on before any firm conclusions should be made.

In line with this, it is also important to clarify a recent assertion by Atroskzo et al. (2019). They wrote that Loscalzo and Giannini conceptualized both workaholism and studyholism as obsessive-compulsive related disorders. However, this is an oversimplification of their 
theorizations. Loscalzo and Giannini, in their papers, constantly specified that Studyholism seems to be more similar to an obsessive-compulsive related disorder than to a behavioral addiction; moreover, they always pointed out that the current literature about problematic overstudying is too scant to reach any conclusion (see Loscalzo and Giannini, 2017b, 2018a, 2018b, 2019a, 2020b, 2020c; Loscalzo, 2021). About workaholism, instead, they suggested a comprehensive model enclosing both internalizing (i.e., obsessive) and externalizing (i.e., addiction) symptoms (Loscalzo and Giannini, 2017a).

Apart from theoretical divergences concerning the conceptualization (and definition) of problematic overworking, the literature highlighted many adverse outcomes associated with it, including higher work-family conflict (in contrast with work engagement, which is usually associated with lower work-family conflict) (e.g., Shimazu et al., 2011; Del Libano et al., 2012; Andreassen et al., 2013; Clark et al., 2013; Simbula and Guglielmi, 2013; Bakker et al., 2014). Work-family conflict refers to a negative spillover effect: attitudes, emotions, and behaviors in the work/life domain (negatively) affect the other domain (Edwards and Rothbard, 2000). Hence, work and family duties are mutually incompatible. More specifically, Greenhaus and Beutell (1985) defined three types of work-family conflict: time-based, strain-based, and behavior-based. Also, they pointed out that there might be a work-to-family conflict (WFC) as well as a family-to-work conflict (FWC).

\subsection{Distance Learning during the COVID-19 pandemic}

In Italy, the first case of COVID-19 was detected on February 20, 2020, in a small North Italy city (Gagliano et al., 2020), and the virus rapidly spread across the Country. On November 5, 2020 (at 10.36 a.m.), Italy counted 759.829 confirmed cases and 39.412 deaths linked to COVID-19 (WHO, 2020). Hence, trying to contain the spread of the virus, the Italian government adopted various measures, including the closure of schools in March 2020, which suddenly posed teachers with the duty of providing DL to students across all school levels. Therefore, among the workers who might have been negatively affected by (unexpected) teleworking, there are teachers (who performed telework in the form of DL), especially those working in the lowest school levels. Younger students are, in fact, less acquainted with the technology. Therefore, it might be more challenging to provide DL to children and pre-adolescents aged 3 to 13 than to students attending secondary schools of second grade (namely, adolescents aged between 14 and 19 years old). Also, for kindergarten teachers, it might be even harder than for other teachers, since it is tricky to use DL for those activities they usually implement to give children some rudimental of drawing, coloring (and even writing, reading, and counting), as their students are very young and their parents must be involved to complete these activities efficiently in an online format.

Adopting teleworking requires change management. Martínex-Sánchez et al. (2008), for instance, showed that having access to Human Resources commitment practices and social benefits is associated with higher adoption of telework. Also, Beno (2018) stressed the importance of an effective leader for the success of teleworking: managers must have effective managerial communication. Though, as Shah and Manna (2020) pointed out in the context of the change to telework due to the COVID-19 pandemic, Indian industries were not ready to implement telework in their organizations since, among various factors, they lacked training and resources. Hence, they stated that organizations should change their 
process and procedures for implementing effective (and not forced) teleworking, including settling adequate technical infrastructure. In line with this, it might be ventured that Italian Schools' Heads were not ready for implementing effective change management, as they faced a sudden, unexpected, and mandatory shift to DL. Hence, DL might have harmed teachers' mood and work-family balance.

Moreover, in line with Beckhard and Harris's formula (1977, 1987), it might be argued that teachers were not ready for the organizational change required by DL. Čudanov, Tornjanski, and Jaško (2019) stated that this formula grounds on the assumption that almost every change that occurs at a large scale might be perceived as a transition, regardless of its type and content. More specifically, the formula suggests that the following elements must be present at the same time to have the required change: i) dissatisfaction with the status quo - employees might not be willing to change if they are satisfied with their current work situation; ii) presence of a compelling vision in the change process - it should be attractive to make employees have a positive attitude towards the required change; iii) having done practical first steps/actions towards the future state - they are critical in the process of materialization of the vision. The multiplication of these three factors must be higher than the resistance to change. Therefore, if any of these three components has a value near zero (or equal to zero), the result of the multiplication will be zero (or near zero) as well: it means that the probability of change to occur will be very low, as the resistance to change is much higher. Hence, the supposition that teachers were not ready for the DL change is based on the following considerations: i) it is hard to believe that teachers were dissatisfied with their status quo, that is, with teaching "in person", as it is the main task of their profession; ii) due to the unexpected health emergency, teachers could not have a vision of the (unforeseen) change; moreover, it might be assumed that Schools' Heads did not have the time to share a vision with the employees - teachers generally received indications from their Schools' Heads without a preliminary discussion as DL needed to be implemented quickly; iii) teachers could not have done practical steps toward DL before the sudden health emergency since the regular way of doing lesson was "in person". Hence, it might be assumed that the multiplication of the three factors will lead to a result near zero, indicating that teachers probably showed high resistance to the changes required by DL, with a consequent negative impact on their lives and work.

Hence, in the context of the current COVID-19 health pandemic, which required teleworking for jobs that never used this type of work, such as teaching, it is critical - from a preventive perspective - to shed light on the impact that the positive and negative type of HWI (i.e., work engagement and workaholism) had on WFC during DL, as well as their impact on DL (perceived DL efficacy and DL negative impact on work and life). This might give valuable insights into the type of attitudes toward work that organizations should foster to preserve their employees' health and productivity during an emergency requiring confinement at home. Moreover, it is critical to analyze the effect of the experienced negative impact on life due to DL (a subset of teleworking) on WFC and negative affect.

\subsection{The present study}

This study aims to analyze how workaholism and work engagement influenced DL, WFC, and negative affect. Moreover, it aims to analyze if the perceived negative impact of DL on 
life influenced WFC and negative affect. Also, it aims to analyze if DL negative impact on work and DL perceived efficacy for students predict negative affect. Finally, it analyzes if there are some differences in DL-related variables concerning gender, area of living (i.e., North, Center, and South Italy), type of school (i.e., kindergarten, primary school, and secondary school of first grade), and type of teacher (i.e., curriculum teacher and teachers working with students who have special needs). More specifically, the hypotheses are:

i) workaholism, since it is usually associated with adverse outcomes (see for a review, Loscalzo and Giannini, 2017a), is a positive predictor of negative affect, WFC, and DL negative impact on both work and life. Moreover, it is a negative predictor of DL perceived efficacy for students;

ii) work engagement, which is usually associated with positive outcomes (e.g., Haar and Roche, 2013, Wojdylo et al., 2014), is a positive predictor of DL perceived efficacy for students and a negative predictor of negative affect, WFC, and DL negative impact on both work and life;

iii) DL negative impact on life (that explicitly involves the work-family conflict) is a positive predictor of WFC; and

iv) DL negative impact on both work and life (implying negative consequences on the two main domains of workers) are positive predictors of negative affect, while DL perceived efficacy for students is a negative predictor.

There are no specific hypotheses about demographic-related differences on DL since, to the best of the author's knowledge, there is no literature concerning DL. In the same line, since the author did not find a validated instrument to evaluate the DL impact on teachers, designing a psychometric sound scale to evaluate DL constitutes a preliminary step.

\section{Research methodology}

\subsection{Participants}

A convenience sample of 587 teachers participated in the study. Most of the participants are females $(94.5 \%)$, and they are aged between 24 and 67 years $(M=48.80, \mathrm{SD}=9.17)$ and living across all Italy: North (40.7\%), Center (42.4\%), and South (16.9\%). Most of them were married $(61.2 \%)$ or living with their partner $(12.8 \%)$; there were also divorced $(5.3 \%)$, separated $(3.9 \%)$, and a few widowers (1.9\%). Finally, some of the participants were engaged $(5.3 \%)$ or single $(9.7 \%)$. Concerning children, $28.1 \%$ of participants did not have children, while there were parents of one child $(22.7 \%)$, two $(41.1 \%)$, three $(6.8 \%)$, or four $(1.2 \%)$ children.

The participants filled the questionnaire between the last days of August and the end of November 2020 (the majority participated between September 28 and October 31; 74.4\%). However, when filling the questionnaire concerning DL, school level, and year in which they were teaching, they were asked to refer to the previous school year, namely, the one affected by the lockdown (that is, the school year 2019/2020). Most of the participants were curricular teachers $(85.0 \%)$ in that school year, while a few were teachers who work with children with special needs $(15.0 \%)$. About the school's level, these are the percentages of 
teachers who worked, respectively, in kindergarten, primary school, and secondary school of first grade: $9.7 \%, 62.2 \%$, and $28.1 \%$.

\subsection{Materials}

\subsubsection{Work-related Inventory (WI-10)}

Loscalzo and Giannini (2019b) created the Work-related Inventory (WI-10) based on their comprehensive workaholism model (Loscalzo and Giannini, 2017a) for evaluating both workaholism and work engagement. The WI-10 is a 10-item (two filler items) self-report instrument, and the response format is a 5-point Likert scale ranging between 1 (Completely disagree) and 5 (Completely agree). Loscalzo and Giannini (2019b) also suggested the cutoff scores for screening four kinds of worker: disengaged workaholic, engaged workaholic, engaged worker, detached worker.

\subsubsection{Work-Family Conflict Scale (WFCS)}

The participants received the Italian validation (Loscalzo, et al. 2019) of the WFCS by Carlson, Kacmar, and William (2000). The WFCS is an 18-item self-report scale whose response format is a 5-point Likert scale ranging from 1 (Completely disagree) to 5 (Completely agree). Through six scales, it allows evaluating the work-family conflict in both its two directions (WFC and FWC) and its three forms (time-based, strain-based, behavioral-based). The scale has been administered in its full version; however, just the three WFC scales have been used.

\subsubsection{Positive and Negative Affect Schedule (PANAS)}

The participants filled the Italian version (Terracciano, McCrae, and Costa, 2003) of the PANAS (Watson, Clark, and Tellegen, 1998), a 20-item self-report instrument for evaluating positive and negative affect. The response format is a 5-point Likert scale ranging from 1 (Very slightly or not at all) to 5 (Extremely). The PANAS is available in a trait and a state version, whose difference is only in the instruction. In this study, it has been administered the state version in its full version; however, just the negative affect scale has been used for the analyses.

\subsubsection{Distance Learning Questionnaire (DLQ)}

To the best of the authors' knowledge, in the literature, there was not available an instrument for evaluating the impact of DL on teachers' work and quality of life and their perception of the efficacy of this type of teaching for students. Hence, a scale with a good factor structure has been developed from an initial pool of 44 items covering DL aspects, as mentioned above. First, Exploratory Factor Analyses (Principal Axis Factoring, Promax rotation) on a random half of the sample $(n=303)$ allowed reducing the number of the items and reach a good and stable factor structure. The analyses highlighted a 16-item and 3-factor solution, with factor loadings ranging between .47 and .99 (see Appendix 1). The three factors have been labelled: i) DL efficacy for students; ii) DL negative impact on work; iii) DL negative impact on life. Next, this factor structure received further support through Confirmatory Factor Analysis (Maximum Likelihood Estimation), which has been 
performed on the other random half of the sample $(n=284)$ : GFI $=.91$; CFI $=.95$; RMSEA $=.063,90 \%$ C.I. $=.051-.075$. The standardized factor loadings are good, ranging between .29 and .96 (see Appendix 1). About factor correlations, there is a positive correlation between DL negative impact on work and life (.44), while DL efficacy on students is negatively correlated with the DL negative impact on both work (-.29) and life (-.21). Finally, the three scales have good internal reliability, as calculated through Cronbach alpha on the total sample $(\mathrm{n}=587)$ : DL efficacy for students, $\alpha=.82$; DL negative impact on work, $\alpha=.87$; DL negative impact on life, $\alpha=.87$.

\subsection{Procedure}

To recruit teachers across all of Italy, and thanks to a graduating student's involvement, the questionnaire link has been spread on social networks. Also, schools have been contacted through the email address provided publicly on the Italian Ministry of Education, University, and Research web page. Hence, an online questionnaire has been administered, including the WI-10, the WFCS, the PANAS, and the DLQ, and some questions about personal data (e.g., gender, age). About the Informed Consent, all the related information was presented on the first page of the questionnaire, asking participants to check the box stating that they agreed to participate in the research by filling the questionnaire on the next pages. The study design complies with the Declaration of Helsinki ethical standards.

\subsection{Data analysis}

The analyses have been performed through SPSS.27 and AMOS.22. The first analyses concern the zero-order correlations of the path analysis model's variables and their skewness and kurtosis. Then, a path analysis (Maximum Likelihood estimate method) analyzed: i) the impact of heavy work investment (i.e., workaholism and work engagement) on DL-related variables (i.e., DL efficacy for students, DL negative impact on work, and DL negative impact on life), WFC, and negative affect; ii) the impact of DL negative impact on life on WFC and negative affect; iii) the impact of DL negative impact on work and of DL efficacy for students on negative affect. The indices and cut-off values to evaluate the fit of the model are: $\chi^{2} / \mathrm{df}$ ratio, which indicates a good fit if its value is less than 3 (Byrne, 2001); Goodness of Fit Index (GFI) and Comparative Fit Index (CFI), whose cut-offs are: <.90 lack of fit, .90-.95 good fit, >.95 excellent fit (Hu and Bentler, 1999); and Root Mean Square Error of Approximation (RMSEA), where a value below .05 indicates excellent fit, while values between .05 and .08 indicate an acceptable fit (Reeve et al., 2007).

Finally, four MANOVAs have been performed to analyze if there are differences in DL variables regarding gender, area of living, type of school, and type of teacher. Bonferroni post-hoc test has been used for independent variables made up of more than two levels.

The number of workers belonging to the four types of worker (i.e., engaged workaholics, $n$ = 49; disengaged workaholics, $n=1$; engaged workers, $n=30$; detached workers, $n=4$ ) does not allow to compare engaged and disengaged workaholics through either parametric or non-parametric analyses; hence, it is not possible to compare them for detecting potential differences in the DL variables. 


\section{Results}

\subsection{Path Analysis Model}

The preliminary analyses are the zero-order correlations among all the variables included in the path analysis model (Table no. 1 shows the results of this analysis), and their skewness and kurtosis. The analyses showed that the variables have a normal distribution since skewness and kurtosis values range between -1 and +1 . The only exceptions are for work engagement (kurtosis $=1.18$ ) and negative affect (skewness $=1.24$ ); however, their values are slightly above +1 . Moreover, the correlation values highlighted that workaholism is associated with higher WFC, negative affect, and DL negative impact on both work and life. Work engagement, instead, has a negative correlation with WFC and negative affect, and a positive correlation with the perceived efficacy of DL on students.

Next, it has been tested the model in which workaholism and work engagement are predictors of DL-related variables, WFC, and negative affect. Moreover, there are paths from DL negative impact on life on WFC and negative affect, and from both DL negative impact on work and DL efficacy for students on negative affect.

The model showed an excellent fit to the data: $\chi^{2} / \mathrm{df}=1.92, p=.07$; GFI $=1.00 ; \mathrm{CFI}=.99$; RMSEA $=.040$ [90\% CI $=.00-.07]$. In sum, workaholism positively predicts the negative impact of DL on both work and life, the three forms of WFC, and negative affect, while it is a negative (but not statistically significant) predictor of DL efficacy for students. In contrast, work engagement negatively predicts the negative impact of DL on both work and life, WFC, and negative affect, while it positively predicts the DL efficacy for students. Also, DL negative impact on life is a positive predictor of WFC. Finally, while DL negative impact on both work and life are positive predictors of negative affect, DL efficacy for students is a negative predictor.

Table no. 1. Zero-order correlations among study variables $(n=587)$

\begin{tabular}{|l|l|l|l|l|l|l|l|l|l|}
\hline & 1 & 2 & 3 & 4 & 5 & 6 & 7 & 8 & 9 \\
\hline 1. WH & - & & & & & & & & \\
\hline 2. WE & $.13^{* * *}$ & - & & & & & & & \\
\hline 3. WFC Time & $.29^{* * *}$ & $-.17^{* * * *}$ & - & & & & & & \\
\hline 4. WFC Strain & $.27^{* * *}$ & $-.26^{* * *}$ & $.60^{* * *}$ & - & & & & & \\
\hline 5. WFC Behavior & $.30^{* * *}$ & $-.16^{* * *}$ & $.35^{* * *}$ & $.43^{* * *}$ & - & & & & \\
\hline 6. PANAS Negative & $.29^{* * *}$ & $-.15^{* * *}$ & $.36^{* * *}$ & $.44^{* * *}$ & $.32^{* * *}$ & - & & & \\
\hline 7. DL Efficacy & -.02 & $.14^{* * * *}$ & -.04 & -.07 & -.06 & $-.19^{* * *}$ & - & & \\
\hline 8. DL on Work & $.18^{* * * *}$ & -.08 & $.19^{* * *}$ & $.18^{* * *}$ & $.21^{* * *}$ & $.25^{* * *}$ & $-.32^{* * *}$ & - & \\
\hline 9. DL on Life & $.24^{* * *}$ & -.07 & $.52^{* * *}$ & $.36^{* * *}$ & $.25^{* * *}$ & $.30^{* * *}$ & $-.17^{* * *}$ & $35^{* * *}$ & - \\
\hline
\end{tabular}

Notes: $\mathrm{WH}=$ Workaholism (Work-related Inventory); WE = Work Engagement (Work-related Inventory); WFC = Work-to-Family Conflict (Work-Family Conflict Scale); PANAS = Positive and Negative Affect Schedule; DL $=$ Distance Learning; DL Efficacy $=$ DL efficacy for students; DL on Work = DL negative impact on work; DL on Life $=$ DL negative impact on life; $* * *=p \leq .001$.

Moreover, the variables whose variance is explained the most are the WFC scales (Time: 31.3\%; Strain: 23.3\%; Behavior: $14.6 \%$ ) and negative affect (19.5\%). Instead, the percentage of explained variance is lower for DL related variables: DL negative impact on life, $6.8 \%$; DL negative impact on work, $4.1 \%$; DL efficacy for students $2.2 \%$. Table no. 2 shows the standardized path weights of the path analysis model. 
Table no. 2. Standardized path weights for each dependent variable of the path analysis model $(n=587)$

\begin{tabular}{|c|c|c|c|}
\hline Dependent Variable & Predictor & $\boldsymbol{\beta}$ & $\boldsymbol{p}$ \\
\hline DL - Efficacy for Students & Workaholism & -.04 & $\mathrm{~ns}$ \\
\hline DL - Negative Impact on Work & Work Engagement & .15 & $<.001$ \\
\hline & Workaholism & .19 & $<.001$ \\
\hline DL - Negative Impact on Life & Work Engagement & -.10 & .013 \\
\hline & Workaholism & .26 & $<.001$ \\
\hline WFC - Time based & Work Engagement & -.10 & .014 \\
\hline & Workaholism & .19 & $<.001$ \\
\hline & Work Engagement & -.17 & $<.001$ \\
\hline WFC - Strain based & DL - Negative Impact on Life & .45 & $<.001$ \\
\hline & Workaholism & .23 & $<.001$ \\
\hline & Work Engagement & -.28 & $<.001$ \\
\hline WFC - Behavior based & DL - Negative Impact on Life & .27 & $<.001$ \\
\hline & Workaholism & .27 & $<.001$ \\
\hline & Work Engagement & -.19 & $<.001$ \\
\hline Negative Affect & DL - Negative Impact on Life & .16 & $<.001$ \\
\hline & Workaholism & .25 & $<.001$ \\
\hline & Work Engagement & -.15 & $<.001$ \\
\hline & DL - Negative Impact on Life & .19 & $<.001$ \\
\hline & DL - Negative Impact on Work & .08 & .043 \\
\hline & DL - Efficacy for Students & -.12 & .001 \\
\hline
\end{tabular}

\subsection{Differences in Distance Learning related variables}

Four MANOVAs have been performed to analyze if there are differences in the DL variables with regards to gender, area of living, type of school (i.e., kindergarten, primary school, and secondary school of first grade), and type of teacher (i.e., curricular teacher or teacher working with special needs children).

About gender, the multivariate test showed a statistically significant effect on DL variables: $F(3,583)=4.09, p=.007$, partial $\eta^{2}=.02$. Though, follow-up ANOVAs showed a statistically significant effect on DL negative impact on life only: $F(1,585)=11.92$, $p<.001$, partial $\eta^{2}=.02$. More specifically, women reported a higher negative impact $(M=20.37 \pm 6.59)$ than males $(M=16.22 \pm 7.00)$.

As far as the area of living is concerned, the multivariate test is statistically significant: $F(6,1164)=8.47, p<.001$, partial $\eta^{2}=.04$. Moreover, follow-up ANOVAs showed a statistically significant effect on all the DL related variables: DL efficacy for students, $F(2,584)=18.85, p<.001$, partial $\eta^{2}=.06$; DL negative impact on work, $F(2,584)=7.37$, $p<.001$, partial $\eta^{2}=.03$; DL negative impact on life, $F(2,584)=7.69, p<.001$, partial $\eta^{2}=.03$. The Bonferroni post-hoc test showed that teachers living in South Italy perceived a higher efficacy of DL for students $(M=39.77 \pm 8.24, p<.001)$ than teachers living both in North $(M=34.50 \pm 9.08)$ and Center $(M=33.39 \pm 8.87)$ Italy. In addition, in the South there 
is a lower negative impact of DL on work $(M=9.48 \pm 6.20)$ than both North $(M=12.02 \pm 6.76, p=.006)$ and Center $(M=12.57 \pm 7.15, p<.001)$ Italy. Finally, they also experienced a lower negative impact on their lives $(M=18.00 \pm 7.04)$ than both North $(M=21.09 \pm 6.00, p<.001)$ and Center $(M=20.08 \pm 6.95, p=.024)$ Italy teachers.

About the type of school, the multivariate test showed a statistically significant effect on DL variables: $F(6,1164)=6.53, p<.001$, partial $\eta^{2}=.03$. More specifically, follow-up ANOVAs showed a statistically significant effect for DL efficacy for students $[F(2,584)=$ $7.82, p<.001$, partial $\left.\eta^{2}=.03\right]$ and DL negative impact on life $[F(2,584)=6.50, p=.002$, partial $\left.\eta^{2}=.02\right]$. The Bonferroni post-hoc test showed that primary school teachers perceived a higher efficacy of DL for students $(M=36.03 \pm 8.95, p=.007)$ than both kindergarten teachers $(M=32.09 \pm 9.63)$ and secondary school of first grade $(M=33.43 \pm 8.95)$. Also, kindergarten teachers experienced a lower negative impact of DL on their lives $(M=17.33 \pm 7.02)$ than both primary $(M=20.69 \pm 6.47, p<.001)$ and secondary school $(M=19.90 \pm 6.77, p=.035)$ teachers.

Finally, the type of teacher has a multivariate statistically significant effect on DL variables: $F(3,583)=5.63, p<.001$, partial $\eta^{2}=.03$. Though, follow-up ANOVAs showed a statistically significant effect on DL efficacy for students only: $F(1,585)=11.18, p<.001$, partial $\eta^{2}=.02$. More specifically, curricular teachers reported a higher level $(M=35.44 \pm 9.04)$ than teacher who work with children with special needs $(M=31.94 \pm 9.06)$.

\section{Discussions}

In the context of the current COVID-19 health crisis, this study aims to analyze how workaholism and work engagement influenced teachers' Distance Learning (DL) and their work-to-family conflict (WFC) and negative affect. Moreover, it also aims to analyze if DL itself influenced WFC and negative affect.

As a preliminary step, due to the lack of an instrument for the evaluation of DL in teachers, it has been developed the Distance Learning Questionnaire (DLQ), which comprehends 16 items and three scales: DL efficacy for students, DL negative impact on work, and DL negative impact on life. Besides its good factor structure, it showed good internal reliability. Hence, the DLQ will be a valuable instrument for future studies aiming to analyze further the impact of DL on teachers' well-being and productivity and their students' well-being and school performance.

Concerning the first research hypothesis, workaholism proved to be (as hypothesized) a predictor of all the variables - except for DL efficacy for students - with beta values ranging from .15 (DL negative impact on work) to .27 (behavior-based WFC). Hence, workaholic teachers experienced a higher negative impact on their work and life due to $D L$, and they also experienced higher WFC (in all its components: time, strain, and behavior) and negative affect. Though, contrary to the hypothesis, workaholism does not predict a lower perceived DL efficacy for students, as this path is not statistically significant.

About work engagement, in line with the second hypothesis, the results showed that it negatively predicts negative affect, WFC (in all three forms), and DL negative impact on 
both work and life. However, as compared to workaholism, its beta values are lower; this suggests that the protective role of work engagement is weaker as compared to the importance of workaholism as a risk factor, especially concerning DL negative effect on life (the beta values are .10 and .19 for work engagement and workaholism, respectively) and negative affect (the beta values are -.15 and .25 for work engagement and workaholism, respectively). However, work engagement has a positive predictive value on DL efficacy for students, signifying that it helps teachers perceive their work as effective, at least to a greater extent than workaholics.

In sum, these results suggest that Schools' Heads should foster work engagement and reduce workaholism in teachers, especially during a health crisis that forces teachers to move to DL, since higher levels of workaholism have been found to be predictive of higher negative affect, higher WFC, and a higher negative impact of DL on both work and life. Thus, workaholism harms teachers, but also their families, students, and organizations. Hence, it is critical reducing workaholism to improve teachers' well-being and quality of work. Even if work engagement has a protective role (and should be increased), it has, in fact, a lower impact than workaholism.

About the third hypothesis, the results supported the postulated positive predictive effect of $D L$ negative impact on life on all the forms of WFC; moreover, the effect is strong for tim e-based WFC and, even if at a lower extent, for strain-based WFC. Therefore, it seems that DL required teachers to devote much more time and energy to work than the work previously done at school, hence depriving them of the right to spend adequate time with their families. The unexpected online format might have imposed to learn how to use appropriately online platforms for lessons and rethink lessons' structure to provide them online in an effective form (also for children with special needs). Hence, as they might not have been well-prepared for all these changes, they might have needed more time for preparing and doing the lessons and might have experienced more strain/distress, which impeded them from being present in the family. Hence, DL might have had a detrimental effect on teachers' ability to balance the time devoted to work and family, increasing their strain due to the changes in their work. Therefore, also considering that schools might need to use DL again in the future, Schools' Heads must provide their employees with useful information about technical and educational issues posed by the DL, as well as technical and psychological support for coping with the changes they are facing (or faced) in their work. In this way, it might be easier for them to optimize the time devoted to work while protecting the balance between work and life.

In line with the last hypothesis, $D L$ negative impact on life is a positive predictor of negative affect, while DL perceived efficacy for students is a negative predictor. This suggests the critical need to implement psychological interventions to reduce the distress perceived by teachers during the DL provided in the past school year (and those who are still working online during the current year). Moreover, it would help to design a training aimed at improving teachers' skills in providing DL of good quality. Also, it would be helpful, aiming to ease the distress, to provide teachers with infrastructure and institutional support for DL. Finally, in line with the hypothesis, $D L$ 's negative impact on work is a positive predictor of negative affect; though, it is just marginally statistically significant and had a low value. This suggests that the target of interventions aimed at preventing negative affect should mainly focus on the impact of DL on life rather than on work. 
Regarding demographic differences in DL variables (no hypotheses provided due to the lack of literature concerning DL), the analyses showed that women experienced a higher negative impact of $D L$ on life, while there is no difference concerning DL impact on work and the perceived efficacy of DL for students. It might be suggested that the higher negative impact experienced by women on their lives is because, probably, women generally report a higher prevalence of psychopathologies (APA, 2013); however, this result might also be because, culturally, men are less acquainted to show their difficulties, especially at an emotional level. Moreover, the analyses highlighted that South Italian teachers perceived a higher DL efficacy for students (and a lower negative impact of DL on their job and their lives) than teachers living in North and Center Italy. Hence, it seems that DL had a lower negative impact in South Italy. Future studies should analyze if this is also evident for other types of jobs that moved to the online/remote format during the COVID-19 pandemic. Moreover, it would be interesting to analyze further these results in teachers to evaluate if some individual and/or situational variables differ among South and North/Center Italy. This could provide critical insights for developing interventions to improve DL efficacy and reduce its negative impact on teachers' well-being.

Concerning school-related variables (no hypotheses provided), primary school teachers perceived a higher DL efficacy for students than teachers working in kindergarten or secondary school of first grade. This result might be because most of the lessons usually provided to primary school children might have been easier adapted to the online format. In secondary schools of first grade, lessons require a higher investment of time and energy from students, and they might have been not motivated by the online format, especially considering the great value of social interactions for pre-adolescents (which was lacking during DL). Therefore, teachers might have felt that their lessons were not effective. In kindergarten, instead, students are usually involved in games and laboratory activities which might have been hard to propose online; moreover, as students are aged between 3 and 5 years, they cannot use an online platform easily. Kindergarten teachers, however, experienced a lower negative impact of DL on their lives than both primary and secondary school teachers: they probably had to devote less time to work than other teachers since they could not provide as many online lessons as the teachers from the other two schools' levels. Finally, curricular teachers reported a higher level of perceived DL efficacy for students than teachers who work with children with special needs. Also in this case, this is possible because doing lessons online for students with special needs might be far more complicated and less effective.

In sum, these results suggest that the previously mentioned training aimed at improving DL efficacy should be targeted especially to kindergarten and secondary school teachers (and to teachers working with children with special needs). In contrast, the interventions aimed at improving the balance between work and life during DL should be mainly addressed to primary and secondary school teachers.

About the limitations of this study, teachers filled the questionnaire referring to the previous school year, while it would have been interesting to gather data when they were involved in DL, namely between March and May 2020. Moreover, most of the participants are females and from primary school. In Italy, teachers are mostly females (78\%; OCSE, 2018); however, in our sample, the percentage of women is much higher $(94.5 \%)$. Moreover, the percentage of teachers living in different areas of Italy (i.e., North, Center, South) are not similar in size: South Italy is less represented. 
Though, this study has the main merit of having highlighted that, during DL, workaholics experienced a higher work-to-family conflict and a higher negative impact of DL on their lives and work, while engaged workers have been protected by these downsides, and they also found their DL to be effective for their students. It also provided valuable insights for preventive and clinical interventions aimed at improving teachers' well-being (and hence the well-being of their families and students, but also the worth of their organization) and the quality of their DL. Finally, to conduct this study, it has been created a scale that evaluates the perceived efficacy of DL and its negative impact on teachers' work and lives, which might be used in future studies aiming to analyze further DL correlates in teachers and students.

\section{Conclusions}

This study highlighted the importance of analyzing the downsides that DL (that is, a subset of teleworking) might have caused to employees, especially those whose job requires faceto-face interactions, such as teaching.

All the hypotheses have been confirmed, except for the assumption that workaholism predicts a lower perceived DL efficacy for students, as this path is not statistically significant. More specifically, this study showed that it is imperative to reduce workaholism to improve teachers' well-being during DL. In fact, work engagement has proved to be a protective factor against the downsides of DL, but its predictive value is lower than that of workaholism. Moreover, based on the results of this study, it seems valuable for Schools' Heads to implement training to help teachers face the technical and educational issues posed by the DL and make them able to provide DL of good quality. They should also provide them with psychological support that might help them cope with the distress felt due to their work changes, which affected their balance between work and life.

Also, this study underlined that women experienced a higher negative impact of DL on their lives, and that South Italian teachers had a lower negative impact on their lives and job due to DL. Hence, it would be interesting to analyze further these demographic differences among other types of jobs. Finally, DL has been perceived as more effective by primary school teachers and curricular teachers. Therefore, the training aimed at improving DL quality should be primarily addressed to kindergarten and secondary school teachers and to teachers working with children with special needs. Instead, the need for balancing the time and energy devoted to work and family should be targeted primarily to teachers working in primary and secondary schools since kindergarten teachers reported a lower negative impact of DL on their lives.

\section{Acknowledgement}

Thanks to a student, and future teacher, that gathered the data for this research. 


\section{References}

American Psychiatric Association, 2013. DSM-5. Diagnostic and statistical manual of mental disorders. $5^{\text {th }}$ ed. Washington, DC: American Psychiatric Association.

Andreassen, C. S., Hetland, J. and Pallesen, S., 2013. Workaholism and work-family spillover in a cross occupational sample. European Journal of Work and Organizational Psychology [e-journal] 22(1), pp.78-87. doi: 10.1080/1359432X.2011.626201

Atroszko, P. A., Demetrovics, Z. and Griffiths, M. D., 2019. Beyond the myths about work addiction: Toward a consensus on definition and trajectories for future studies on problematic overworking. A response to the commentaries on: Ten myths about work addiction (Griffiths et al., 2018). Journal of Behavioral Addictions [e-journal] 8(1), pp.7-15. doi: 10.1556/2006.8.2019.11

Babic, A., Stinglhamber, F., Barbier, M. and Hansez, I., 2019. Work environment and work-to-family conflict: examining the mediating role of heavy work investment. Journal of Management \& Organization [e-journal] pp.1-24. doi: 10.1017/jmo.2019.40

Beckhard, R. F. and Harris, R. T., 1977. Organizational Transitions: Managing complex $i$ change. MA: Addison Wesley Publishing Company.

Beckhard, R. F. and Harris, R. T., 1987. Organizational Transitions: Managing complex change. Reading, MA: Addison-Wesley.

Beno, M., 2018. Managing telework from an Austrian manager's perspective. In: Á. Rocha, H. Adeli, L.P. Reis and S. Costanzo eds., 2018. Trends and Advances in Information Systems and Technologies. Cham: Springer, pp.16-29.

Bakker, A. B., Shimazu, A., Demerouti, E., Shimada, K. and Kawakami, N., 2014. Work engagement versus workaholism: A test of the spillover crossover model. Journal of Managerial Psychology [e-journal] 29(1), pp.63-80. doi: 10.1108/JMP-05-2013-0148

Carlson, D. S., Kacmar, K. M. and William, L. J., 2000. Construction and initial validation of a multidimensional measure of work family conflict. Journal of Vocational Behavior [e-journal] 56, pp.249-276. doi: 10.1006/jvbe.1999.1713

Clark, M. A., Michel, J. S., Stevens, G. W., Howell, J. W. and Scruggs, R. S., 2013. Workaholism, work engagement and work-home outcomes: Exploring the mediating role of positive and negative emotions. Stress and Health [e-journal] 30, pp.287-300. doi: $10.1002 / \mathrm{sm} .2511$

Čudanov, M., Tornjanski, V. and Jaško, O., 2019. Change equation effectiveness: Empirical evidence from south-east Europe. Business Administration and Management [e-journal] 22(1), pp.99-114. doi: 10.15240/TUL/001/2019-1-007

Del Libano, M., Llorens, S., Salanova, M. and Schaufeli, W.B., 2012. About the dark and bright sides of self-efficacy: Workaholism and work engagement. The Spanish Journal of Psychology [e-journal] 15(2), pp.688-701. doi: 10.5209/rev_SJOP.2012. v15.n2.38883

Edwards, J. E. and Rothbard, N. P., 2000. Mechanisms linking work and family: Clarifying the relationship between work and family constructs. Academy of Management Review [e-journal] 25, pp.178-199. doi: 10.2307/259269

Gagliano, A., Villani, P. G., Cò, F. M., Manelli, A., Paglia, S., Bisagni, P. A. G. and Lombardo, M., 2020. 2019-nCov's epidemic in middle province of northern Italy: 
Impact, logistic and strategy in the first line hospital. Disaster Medicine and Public Health Preparedness [e-journal] 24, pp.1-15. doi: 10.1017/dmp.2020.51

Greenhaus, J. H. and Beutell, N. J., 1985. Sources of conflict between work and family roles. Academy of Management Review [e-journal] 10, pp.76-78. doi: 10.2307/258214

Haare, J. and Roche, M., 2013. Three-way interaction effects of workaholism on employee well-being: Evidence from blue-collar workers in New Zealand. Journal of Management and Organization [e-journal] 19(2), pp.134-149. doi: 10.1017/ jmo.2013.10

Houlfort, N., Philippe, F.L., Vallerand, R.J. and Ménard, J. 2014. On passion and heavy work investment: personal and organisational outcomes. Journal of Managerial Psychology [e-journal] 29(1), pp.25-45. doi: 10.1108/JMP-06-2013-0155

Hu, L. and Bentler, P. M., 1999. Cutoff criteria for fit indexes in covariance structure analysis: Conventional criteria versus new alternatives. Structural Equation Modeling [e-journal] 6(1), pp.1-55. doi: 10.1080/10705519909540118

Kardefelt-Winther, D., 2015. Commentary on: Are we overpathologizing everyday life? A tenable blueprint for behavioral addiction research. Problems with atheoretical and confirmatory research approaches in the study of behavioral addictions. Journal of Behavioral Addictions [e-journal] 4(3), pp.126-129. doi: 10.1556/2006.4.2015.019

Loscalzo, Y., 2021. Studyholism and Study Engagement: What about the role of perfectionism, worry, overstudy climate, and type of school in adolescence? International Journal of Environmental Research and Public Health [e-journal] 18(3), p.910. doi: 10.3390/ijerph18030910

Loscalzo, Y. and Giannini, M., 2017a. Clinical conceptualization of workaholism: A comprehensive model. Organizational Psychology Review [e-journal] 7(4), pp.306329. doi: $10.1177 / 2041386617734299$

Loscalzo, Y. and Giannini, M., 2017b. Studyholism or study addiction?. A comprehensive model for a new clinical condition. In: A. M. Columbus ed., 2017. Advances in Psychology Research. New York: Nova Publisher, pp.19-37.

Loscalzo, Y. and Giannini, M., 2018a. Response to: Theoretical and methodological issues in the research on study addiction with relevance to the debate on conceptualising behavioural addictions: Atroszko (2018). Psychiatria i Psychologia Kliniczna, 18(4), pp.426-430. doi: 10.15557/PiPK.2018.0051

Loscalzo, Y., Giannini, M., 2018b. Problematic overstudying: Studyholism or Study Addiction?. Commentary on: Ten myths about work addiction. Journal of Behavioral Addictions [e-journal] 7(4), pp.867-870. doi: 10.1556/2006.7.2018.124

Loscalzo, Y. and Giannini, M., 2019a. Heavy Study Investment in Italian College students. An analysis of Loscalzo and Giannini's (2017) Studyholism comprehensive model. Frontiers in Psychiatry [e-journal] 10, p.489. doi: 10.3389/fpsyt.2019.00489

Loscalzo, Y. and Giannini, M., 2019b. What type of worker are you? Work-Related Inventory (WI-10): A comprehensive instrument for the measurement of workaholism. WORK: A Journal of Prevention, Assessment and Rehabilitation [e-journal] 62(3), pp.383-392. doi: 10.3233/WOR-192875 
Loscalzo, Y. and Giannini, M., 2020b. Studyholism Inventory (SI-10): A short instrument for evaluating study obsession in the heavy study investment framework. European Journal of Psychology [e-journal] 16(4), pp.688-706. doi: 10.5964/ejop.v16i4.1911

Loscalzo, Y. and Giannini, M., 2020c. When Studying Becomes an Obsession: The Studyholism Inventory - Extended Version (SI-15). Current Psychology, Online Advanced. [e-journal] Doi: 10.1007/s12144-020-01168-3

Loscalzo, Y., Raffagnino, R., Gonnelli, C. and Giannini, M., 2019. Work-Family Conflict Scale: Psychometric properties of the Italian version. SageOpen [e-journal] 9(3). doi: $10.1177 / 2158244019861495$

Martínez-Sánchez, A., Pérez-Pérez, M., Vela-Jiménez, M. J. and de-Luis-Carnicer, P., 2008. Telework adoption, change management, and firm performance. Journal of Organizational Change Management [e-journal] 21(1), pp.7-31. doi: 10.1108/09534810810847011

Organization for Economic Co-operation and Development, 2018. Results from TALIS 2018. [online] Available at: <https://www.oecd.org/education/talis/TALIS2018_ CN_ITA_it.pdf $>$ [Accessed 14 June 2021].

Rabenu, E. and Aharoni-Goldenberg, S., 2017. Understanding the relationship between overtime and burnout. International Studies of Management \& Organization [e-journal] 47(4), pp.324-335. doi: 10.1080/00208825.2017.1382269

Rabenu, E., Shkoler, O., Lebron, M.J. and Tabak, F., 2019. Heavy-work investment, job engagement, managerial role, person-organisation value congruence, and burnout: A moderated-mediation analysis in USA and Israel. Current Psychology [e-journal] pp.118. doi: 10.1007/s12144-019-00423-6

Reeve, B. B., Hays, R., D., Bjorner, J. K., Cook, K. F., Crane, P. K., Teresi, J. A., Thissen, D., Revicki, D. A., Weiss, D. J., Hambleton, R. K., Liu, H., Gershon, R., Reise, S. P., Lai, J. and Cella, D., 2007. Psychometric Evaluation and Calibration of Health Related Quality of Life Item Banks: Plans for the Patient-Reported Outcomes Measurement Information System (PROMIS). Medical Care [e-journal] 45(5), pp.S22-S31. doi: 10.1097/01.mlr.0000250483.85507.04

Schaufeli, W.B., 2016. Heavy work investment, personality and organisational climate. Journal of Managerial Psychology [e-journal] 31(6), pp.1057-1073. doi: 10.1108/JMP07-2015-0259

Shah, J. and Manna, I., 2020. An empirical assessment of telework readiness on Indian industries. Journal of Organisation and Human Behaviour, 9, pp.50-60.

Shimazu, A., Demerouti, E., Bakker, A. B., Shimada, K. and Kawakami, N., 2011. Workaholism and well-being among Japanese dual-earner couples: A spillover crossover perspective. Social Science and Medicine [e-journal] 73, pp.399-409. doi: 10.1016/j.socscimed.2011.05.049

Simbula, S. and Guglielmi, D., 2013. Engaged sì, workaholic no: Il ruolo di engagement e workaholism sulla salute e il benessere dei dirigenti scolastici. [Engaged yes, Workaholic no: The role of engagement and workaholism on health and well-being of School's Heads] Giornale Italiano di Psicologia [e-journal] 40(1), pp.195-207. doi: $10.1421 / 73991$

Snir, R. and Harpaz, I., 2012. Beyond workaholism: Towards a general model of heavy work investment. Human Resource Management Review [e-journal] 22, pp.232-243. doi: $10.1027 / / 1015-5759.19 .2 .131$ 
Terracciano, A., McCrae, R.R. and Costa, P.T. Jr., 2003. Factorial and construct validity of the Italian positive and negative affect schedule (PANAS). European Journal of Psychological Assessment [e-journal] 19, pp.131-141. doi: 10.1027//10155759.19.2.131

Van Beek, I., 2014. Understanding the dark and bright sides of heavy work investment: Psychological studies on workaholism and work engagement. PhD. Utrecht University.

Van Beek, I., Taris, T. W. and Schaufeli, W. B., 2011. Workaholic and work engaged employees: Dead ringers or worlds apart? Journal of Occupational Health Psychology [e-journal] 16(4), pp.468-482. doi: 10.1037/a0024392

Van Beek, I., W. Taris, T., B. Schaufeli, W. and Brenninkmeijer, V., 2013. Heavy work investment: its motivational make-up and outcomes. Journal of Managerial Psychology [e-journal] 29(1), pp.46-62. doi: 10.1108/JMP-06-2013-0166

Watson, D., Clark, L.A. and Tellegen, A., 1998. Development and validation of brief measure of positive and negative affect: The PANAS scales. Journal of Personality and Social Psychology [e-journal] 54, pp.1063-1070. doi: 10.1037/0022-3514.54.6.1063

Wojdylo, K., Baumann, N., Fischbach, L. and Engeser, S., 2014. Live to work or love to work: Work craving and work engagement. Plos One [e-journal] 9(10), e106379. doi: 10.1371/journal.pone.0106379

World Health Organization, 2020. WHO Coronavirus Disease (COVID-19) Dashboard. [onlien] Available at: <https://covid19.who.int/region/euro/country/it> [Accessed 5 November 2020]. 
Appendix 1. Distance Learning Questionnaire. Exploratory $($ EFA, $\mathbf{n}=303$ ) and Confirmatory $(\mathrm{CFA}, \mathbf{n}=\mathbf{2 8 4})$ Factor Analyses' results.

\begin{tabular}{|c|c|c|c|c|}
\hline Item & & $\begin{array}{l}\text { DL } \\
\text { efficacy } \\
\text { for } \\
\text { students }\end{array}$ & $\begin{array}{c}\text { DL } \\
\text { negative } \\
\text { impact on } \\
\text { work }\end{array}$ & $\begin{array}{c}\text { DL } \\
\text { negative } \\
\text { impact on } \\
\text { life }\end{array}$ \\
\hline \multirow[t]{2}{*}{ 7. My students followed DL with attention } & EFA & .83 & & \\
\hline & CFA & .88 & & \\
\hline \multirow[t]{2}{*}{ 8. My students actively participated to DL } & EFA & .80 & & \\
\hline & CFA & .90 & & \\
\hline \multirow{2}{*}{$\begin{array}{l}\text { 2. At the end of the school year, I have } \\
\text { achieved all the objectives foresee by the } \\
\text { school program }\end{array}$} & EFA & .70 & & \\
\hline & CFA & .46 & & \\
\hline \multirow{2}{*}{$\begin{array}{l}5 \text {. I have been able to reach all my students } \\
\text { equally }\end{array}$} & EFA & .70 & & \\
\hline & CFA & .53 & & \\
\hline \multirow{2}{*}{$\begin{array}{l}\text { 6. The relationship with the students has been } \\
\text { kept unchanged from that preceding the DL }\end{array}$} & EFA & .67 & & \\
\hline & CFA & .47 & & \\
\hline \multirow{2}{*}{$\begin{array}{l}\text { 4. It has been possible to carry out the goal of } \\
\text { inclusion also with DL }\end{array}$} & EFA & .53 & & \\
\hline & CFA & .40 & & \\
\hline \multirow{2}{*}{$\begin{array}{l}\text { 1. I am satisfied with the DL provided to my } \\
\text { students }\end{array}$} & EFA & .49 & & \\
\hline & CFA & .41 & & \\
\hline \multirow{2}{*}{$\begin{array}{l}\text { 3. In the next school year, it will not be } \\
\text { necessary to thoroughly review the topics } \\
\text { covered with the DL }\end{array}$} & EFA & .47 & & \\
\hline & CFA & .29 & & \\
\hline \multirow{2}{*}{$\begin{array}{l}\text { 11. With DL, my motivation to do lessons has } \\
\text { decreased }\end{array}$} & EFA & & .99 & \\
\hline & CFA & & .96 & \\
\hline \multirow{2}{*}{$\begin{array}{l}\text { 10. With DL, my desire to do lessons has } \\
\text { decreased }\end{array}$} & EFA & & .93 & \\
\hline & CFA & & .95 & \\
\hline \multirow{2}{*}{$\begin{array}{l}\text { 12. With DL, my concentration at work has } \\
\text { decreased }\end{array}$} & EFA & & .65 & \\
\hline & CFA & & .63 & \\
\hline \multirow{2}{*}{$\begin{array}{l}\text { 9. With DL, the quality of my teaching has } \\
\text { worsened }\end{array}$} & EFA & & .61 & \\
\hline & CFA & & .64 & \\
\hline \multirow{2}{*}{$\begin{array}{l}\text { 14. I had difficulty in dedicating myself to } \\
\text { relaxing moments and/or with my family, } \\
\text { because I was too busy with DL }\end{array}$} & EFA & & & .95 \\
\hline & CFA & & & .68 \\
\hline \multirow{2}{*}{$\begin{array}{l}\text { 13. With DL, I had difficulties in } \\
\text { "disconnecting" from work }\end{array}$} & EFA & & & .81 \\
\hline & CFA & & & .50 \\
\hline \multirow{2}{*}{$\begin{array}{l}\text { 15. The commitments requested by DL have } \\
\text { had a negative effect on my mood }\end{array}$} & EFA & & & .77 \\
\hline & CFA & & & .90 \\
\hline \multirow{2}{*}{$\begin{array}{l}\text { 16. The commitments requested by DL have } \\
\text { had a negative effect on my family and social } \\
\text { relationships }\end{array}$} & EFA & & & .73 \\
\hline & CFA & & & .83 \\
\hline
\end{tabular}

Note: $\mathrm{DL}=$ Distance Learning. 